\title{
Nota técnica \\ CONTENIDO TOTAL Y DISPONIBILIDAD DE NUTRIMENTOS EN DOS MUESTRAS DE CENIZAS EXPULSADAS EN ENERO DEL 2010 POR EL VOLCÁN TURRIALBA, COSTA RICA
}

\author{
Juan Carlos Méndez ${ }^{1 / *}$, Floria Bertsch ${ }^{*}$
}

\begin{abstract}
Palabras clave: Cenizas volcánicas, solubilidad, Volcán Turrialba, disponibilidad de nutrientes, Andisoles. Keywords: Volcanic ashes, solubility, Turrialba Volcano, nutrient availability, Andisols.
\end{abstract}

Recibido: 07/02/11

\section{RESUMEN}

En enero del 2010 y a una distancia aproximada de $10 \mathrm{~km}$ del cráter principal se recolectaron 2 muestras de cenizas recién expulsadas por el Volcán Turrialba, Costa Rica, con el objetivo de analizar el contenido total y el porcentaje disponible de los elementos en el corto plazo. Para analizar las cantidades totales, las muestras se digirieron con $\mathrm{HNO}_{3}$ al $70 \%$ y los elementos se determinaron por Espectroscopía de Emisión Atómica con Plasma (ICP), mientras que para determinar la cantidad de elementos "disponibles en forma inmediata" se realizó una extracción con las soluciones $\mathrm{KCl}$ y Olsen Modificada. Además, para estudiar la solubilidad de las cenizas en agua, se sometió la muestra 1, a soluciones con 3 distintos $\mathrm{pH}(4,5,5$ y 6,7$)$ y a 4 tiempos de agitación $(0,0,5,4$ y 24 h) con 3 repeticiones en cada caso. Después de la agitación se determinó la conductividad eléctrica así como el pH en la solución y se analizaron los elementos disueltos por medio del ICP. Los contenidos totales promedio presentes en las cenizas fueron, de mayor a menor cantidad, Fe (13 300), $\mathrm{Ca}$ (8700), $\mathrm{Mg}$ (2300), K (750), S (700), P (450), Mn (79), Zn

1 Autor para correspondencia. Correo electrónico: juancarlos.mendez@ucr.ac.cr

Aceptado: 20/07/11

\section{ABSTRACT}

Total content and nutrients availability in two samples of ash eject by the Turrialba Volcano, Costa Rica in January 2010. In January 2010, at a distance of approximately $10 \mathrm{~km}$ from the main crater, 2 samples of ashes ejected by the Turrialba Volcano, Costa Rica, were collected with the objective of analizing their total content of elements, and the percentage available in the short time. To analyze the total amount of elements, both samples were digested with $\mathrm{HNO}_{3}(70 \%)$, and the elements were determined by Atomic Emission Spectroscopy Plasma (ICP), while and to determine the amount of "immediately available" elements in the samples, $\mathrm{KCl}(1 \mathrm{~N})$ and Modified Olsen extractants were used. Moreover, to study the ashes' solubility in water, sample 1 was dissolved at 3 different $\mathrm{pH}(4,5.5$ and 6.7), and with 4 agitation times $(0,0.5,4$ and $24 \mathrm{~h})$, with 3 repetitions in each case. After each agitation time the Electrical Conductivity and the $\mathrm{pH}$ of the resulting solution were determined, and the amount of elements dissolved in the solution was analyzed by ICP. The total average contents present in the ashes

\footnotetext{
* Centro de Investigaciones Agronómicas, Universidad de Costa Rica. San José, Costa Rica.
} 
(38), $\mathrm{Cu}(33)$ y B (31) mg. $\mathrm{kg}^{-1}$. En cuanto a la disponibilidad con la solución extractora, se obtuvo que sólo un $0,2 \%$ del contenido total de Fe se presentó en forma disponible; para los demás elementos los porcentajes correspondieron a: $8-11 \%$ para $\mathrm{Ca}, 0,5 \%$ para $\mathrm{Mg}, 6-15 \%$ para $\mathrm{K}, 10-13 \%$ para $\mathrm{S}, 2-7 \%$ para $\mathrm{P}, 0-3 \%$ para $\mathrm{Mn}, 2-7 \%$ para Zn y 0-3\% para $\mathrm{Cu}$. En los análisis de solubilidad en agua no se detectó presencia de $\mathrm{P}, \mathrm{Zn}, \mathrm{Cu}$ y Mn a ningún $\mathrm{pH}$ de agua ni tiempo de agitación. Para los restantes elementos, excepto el $\mathrm{K}$ que no mostró una tendencia definida, se observaron aumentos significativos en la cantidad disuelta en agua al aumentar el tiempo de agitación a los $3 \mathrm{pH}$ iniciales. Además se observó un efecto "buffer" por parte de la ceniza al disolverse, ya que, sin importar el $\mathrm{pH}$ inicial que tuviera el agua, todos las condiciones tendieron a llevar el $\mathrm{pH}$ de la solución a valores cercanos a 6,7.

\section{INTRODUCCIÓN}

La actividad volcánica y la consecuente deposición de cenizas sobre los lugares aledaños a un cono, conllevan a la constante formación y rejuvenecimiento de los suelos ubicados en estos sitios. Según Alvarado et al. (2001) la formación de suelos derivados de cenizas volcánicas en Costa Rica, es un proceso que se da con relativa rapidez por lo que es común encontrar que los horizontes superficiales son más nuevos que los subsuperficiales.

Besoaín (1972) señala que desde la deposición de las cenizas volcánicas hasta la formación de alofana se da una secuencia progresiva en la que se distinguen 4 etapas: iónica, coloidal, paracristalina y cristalina; durante este proceso muchos nutrientes minerales pueden ser liberados hacia la solución del suelo (Nanzyo 2002).

A mediano y largo plazo las ventajas nutricionales sobre la fertilidad de los suelos causadas por la adición recurrente y meteorización de cenizas volcánicas han sido documentadas frecuentemente (Dahlgren et al. 1999 y Ugolini were, from higher to lower amounts, Fe (13 300), Ca (8700), Mg (2300), K (750), S (700), P (450), $\mathrm{Mn}$ (79), Zn (38), Cu (33) and B (31) mg.kg-1. As to the immediate availability in the extractant solution in relation to total content, $\mathrm{Fe}$ was only $0.2 \%$ available, and for the rest of the elements the percentages were: $8-11 \%$ for $\mathrm{Ca}, 0.5 \%$ for $\mathrm{Mg}, 6-15 \%$ for $\mathrm{K}, 10-13 \%$ for $\mathrm{S}, 2-7 \%$ for $\mathrm{P}, 0-3 \%$ for $\mathrm{Mn}, 2-7 \%$ for $\mathrm{Zn}$, and $0-3 \%$ for $\mathrm{Cu}$. In the analyses of water solubility no presence of $\mathrm{P}, \mathrm{Zn}$, $\mathrm{Cu}$, or $\mathrm{Mn}$ was detected at any initial water $\mathrm{pH}$ or agitation time. For the rest of the elements, except for $\mathrm{K}$ which showed no defined tendency, significant increases in the amount dissolved in water were shown with increases in agitation time at the 3 different initial $\mathrm{pH}$ of water. Also, the dissolved ash showed a "buffer" effect since, regardless of the initial water $\mathrm{pH}$, the solution $\mathrm{pH}$ increased to around 6.7 under all conditions.

y Dahlgren 2002). No obstante en muchas ocasiones, la deposición de materiales volcánicos no implica necesariamente una mejora inmediata en las propiedades nutricionales del suelo.

La solubilidad inicial de las cenizas volcánicas depende en gran medida de la composición y cristalografía de las mismas; un ejemplo de ello son las variaciones en la cantidad de aniones y cationes hallados por Bornemiza (1971) al extraer con agua cenizas frescas de los volcanes Irazú y Arenal.

En el caso de la Cordillera Volcánica Central de Costa Rica se ha reportado que la composición del material volcánico depositado es principalmente de origen andesítico-basáltico (Castillo 1984), y para el caso específico del Volcán Turrialba, Reagan et al. (2006) indican que de las últimas 6 erupciones realizadas por este volcán, 5 de ellas expulsaron material con composición andesítica-basáltica y solo una tuvo características de andesita-silícica.

Es por esta razón que es importante estudiar las características químicas y la solubilidad que tienen las cenizas expulsadas durante un 
período de actividad volcánica, ya que esto permitirá tener desde un punto de vista agronómico, una idea de los posibles efectos inmediatos de la ceniza en el medio sobre el cual es depositada. De acuerdo con Nanzyo (2002) a pesar de que las características de los materiales recién depositados son bastante diferentes en muchos aspectos a las que tiene un Andisol maduro, es importante estudiar las propiedades de las cenizas recién eruptadas ya que es fácilmente comprensible que con el transcurrir de los años dichos materiales darán origen a un tipo particular de suelos.

El presente estudio tuvo como objetivo realizar una evaluación preliminar del contenido total y de la disponibilidad de elementos de las cenizas frescas expulsadas por el Volcán Turrialba de Costa Rica en enero del 2010, basándose en los artículos publicados por Bornemisza y Morales (1969) y Chaverri y Alvarado (1979) con las cenizas del Volcán Irazú y Bornemisza (1971) con las del Volcán Arenal inmediatamente después de ocurrir erupciones en estos volcanes.

\section{MATERIALES Y MÉTODOS}

\section{Recolección de las muestras de cenizas}

Para realizar el presente estudio se recolectaron 2 muestras de cenizas expulsadas por el Volcán Turrialba en enero del 2010. La muestra 1 fue recolectada a partir de material depositado sobre las hojas de un cultivo de coliflor un día después de la primera erupción, en una finca de La Pastora de San Juan de Chicuá, ubicada aproximadamente $10 \mathrm{~km}$ al sureste del cráter del Volcán Turrialba. Por su parte, la muestra 2 fue recolectada de una superficie de cemento sobre la que se había depositado una capa considerable de ceniza. La recolección de esta muestra la efectuaron ingenieros agrónomos del Ministerio de Agricultura y Ganadería durante una visita de reconocimiento de daños en la zona más afectada (a un diámetro menor a los $5 \mathrm{~km}$ del cráter). Ambas muestras fueron llevadas al Laboratorio de Análisis de Suelos y Foliares del Centro de Investigaciones Agronómicas de la Universidad de Costa Rica (LSF/CIA-UCR) para realizar las respectivas determinaciones.

\section{Determinación de la composición total de las cenizas y de elementos extraíbles a corto plazo}

Con el objetivo de analizar el contenido total de $\mathrm{Ca}, \mathrm{Mg}, \mathrm{K}, \mathrm{P}, \mathrm{Zn}, \mathrm{Cu}, \mathrm{Fe}, \mathrm{Mn}, \mathrm{S}$ y $\mathrm{B}$, tanto la muestra 1 como la muestra 2 se pusieron a secar en una estufa a una temperatura de $45^{\circ} \mathrm{C}$ por un período aproximado de $24 \mathrm{~h}$. Después de esto ambas muestras fueron digeridas con $\mathrm{HNO}_{3}$ al $70 \%$ en microondas a $180^{\circ} \mathrm{C}$ y 1000 watts de potencia por $25 \mathrm{~min}$; los elementos se determinaron por medio de Espectroscopía de Emisión Atómica con Plasma (ICP), según la metodología citada por Isaac y Johnson (1997).

Por otro lado, para determinar el porcentaje disponible o fracción fácilmente extraíble de cada uno de estos elementos, se les practicó el procedimiento convencional utilizado en el LSF para efectuar el diagnóstico nutricional de muestras de suelos. Este procedimiento consiste en el uso de la solución $\mathrm{KCl} 1 \mathrm{~N}$ para la extracción de Ca y Mg, y la solución Olsen Modificada para $\mathrm{K}, \mathrm{P}, \mathrm{Zn}, \mathrm{Fe}, \mathrm{Cu}$ y $\mathrm{Mn}$, determinados en el espectrofotómetro de absorción atómica, excepto el $\mathrm{P}$ que se determina colorimétricamente en un autoanalizador de inyección de flujo (Henríquez y Cabalceta 1999). El S se extrajo con Fosfato de Calcio y se determinó por turbidimetría según el procedimiento recomendado por Diaz-Romeu y Hunter (1978).

\section{Determinación de la solubilidad de las cenizas en agua}

Para estudiar la solubilidad de las cenizas en agua, se tomaron $10 \mathrm{ml}$ de ceniza de la muestra 1, se les agregó $25 \mathrm{ml}$ de agua ajustada con $\mathrm{HCl}$ a 3 diferentes valores de $\mathrm{pH}$ inicial (4; 5,5 y 7) y se les sometió a 4 tiempos de agitación $(0$; 0,$5 ; 4$ y 24 h). Cada tratamiento se repitió 3 veces. Una vez finalizado el tiempo de agitación de cada uno de los tratamientos se procedió a determinar la conductividad eléctrica (CE) y el $\mathrm{pH}$ de la 
solución resultante. Además, el sobrenadante se filtró para determinar la cantidad de elementos disueltos luego de la agitación mediante el ICP.

\section{Análisis de datos}

Para comparar los contenidos totales y los porcentajes disponibles de elementos en las muestras de cenizas, las unidades se transformaron a mg. $\mathrm{kg}^{-1}$. Las cantidades de elementos disponibles en la solución extractora, los cuales son expresados en términos de $\operatorname{cmol}(+) .1^{-1}$ y mg..$^{-1}$, fueron transformados a unidades de mg. $\mathrm{kg}^{-1}$ mediante la determinación de la densidad aparente promedio de las muestras de cenizas, mediante el procedimiento descrito por Henríquez y Cabalceta (1999). El valor de la densidad de las cenizas fue de 1,1 g.ml ${ }^{-1}$.

Los resultados de solubilidad de las cenizas en agua se sometieron a un análisis de varian$\mathrm{za}(\mathrm{p} \leq 0,05)$ para cada $\mathrm{pH}$ inicial de la solución, con el fin de verificar si había diferencias significativas entre los diferentes tiempos de agitación. Se utilizó una prueba de Diferencia Mínima Significativa (DMS) Fisher $(\mathrm{p} \leq 0,05)$ para establecer las medias entre cada grupo de datos. El análisis de los datos se realizó con el programa Infostat.

\section{RESULTADOS Y DISCUSIÓN}

\section{Composición total de las cenizas y porcentaje de elementos disponibles}

En el Cuadro 1 se presentan los contenidos totales de elementos, tanto para la muestra 1 como para la muestra 2 , además de la cantidad de elementos disponibles en la solución extractora. El orden de abundancia total de los elementos, de mayor a menor cantidad fue el siguiente: $\mathrm{Fe}>\mathrm{Ca}>\mathrm{Mg}>\mathrm{K}=\mathrm{S}>\mathrm{P}>>\mathrm{Mn}>\mathrm{Zn}=\mathrm{Cu}=\mathrm{B}$. Los resultados muestran que a pesar del alto contenido de Fe total presente en las cenizas solo un $0,2 \%$ de este elemento se encuentra disponible al ser extraído con solución extractora; lo mismo ocurre con el $\mathrm{Mg}, \mathrm{Cu}$ y $\mathrm{Mn}$, en los cuales la cantidad fácilmente extraíble de estos elementos con respecto al total es menor al $1 \%$.

Por otro lado, los elementos que presentaron los porcentajes de disponibilidad más altos en solución extractora fueron el Ca, K y S, sin embargo, ninguno alcanzó valores mayores al $16 \%$.

Al observar los bajos porcentajes de disponibilidad de elementos en las cenizas frescas podría esperarse que la deposición de estos materiales no implique a muy corto plazo una mejora significativa en las propiedades nutricionales

Cuadro 1. Contenido total elementos $\left(\mathrm{mg}_{\mathrm{kg}} \mathrm{kg}^{-1}\right)$ y \% disponible en solución KCl-Olsen en 2 muestras de cenizas del Volcán Turrialba.

\begin{tabular}{ll|llllllllll}
\hline & & $\mathrm{Ca}$ & $\mathrm{Mg}$ & $\mathrm{K}$ & $\mathrm{P}$ & $\mathrm{Zn}$ & $\mathrm{Cu}$ & $\mathrm{Fe}$ & $\mathrm{Mn}$ & $\mathrm{S}$ & $\mathrm{B}$ \\
\hline & muestra 1 & 7600 & 2300 & 700 & 500 & 43 & 32 & 14435 & 86 & 600 & 33 \\
Contenido total $\left({\left.\mathrm{mg} . \mathrm{kg}^{-1}\right)}\right.$ & muestra 2 & 9800 & 2300 & 800 & 400 & 33 & 34 & 12165 & 71 & 800 & 29 \\
\hline $\begin{array}{l}\text { Cantidad disponible } \\
\text { (mg.kg-1) }\end{array}$ & muestra 1 & 842 & 11 & 103 & 13 & 1 & $\mathrm{ND}$ & 26 & $\mathrm{ND}$ & 78 & - \\
\hline $\begin{array}{l}\text { \% Disponible en KCl-Olsen } \\
\text { muestra 2 }\end{array}$ & 809 & 11 & 46 & 24 & 2 & 1 & 26 & 2 & 79 & - \\
\hline
\end{tabular}


presentes en el suelo, que coincide con lo reportado por Soley (1966), quien al agregar diferentes cantidades de ceniza a un latosol encontró una mejora únicamente en las propiedades físicas del suelo, y no así en las propiedades químicas.

Aunado a esto con el pasar del tiempo es posible que la fracción disponible de nutrientes se vea aún más reducida, ya que de acuerdo con lo encontrado por Chaverri y Alvarado (1979) al analizar los cambios de las propiedades químicas de las cenizas del Volcán Irazú con el tiempo, se evidenció una disminución en la cantidad de cationes intercambiables, especialmente los monovalentes. Al respecto Bornemisza (1971) señala que si bien los iones que entran en solución provenientes de estos materiales pueden contribuir en alguna medida en la fertilidad de los suelos, la tasa a la que estos se pierden es rápida y sostenida, lo cual explica en gran medida la velocidad con la que se forman los suelos derivados de cenizas volcánicas.

En un período de tiempo mayor, es muy posible que los efectos de las deposiciones de las cenizas sobre el estado de la fertilidad y el rejuvenecimiento de los suelos sí puedan ser observados. Un ejemplo de ellos es lo citado por Bornemisza y Morales (1969), quienes mencionan que en Guatemala, 4 años después de una expulsión de cenizas, se dio un incremento en la producción de café, atribuible en gran medida al aporte de bases solubles ( $\mathrm{K}, \mathrm{Ca}$ y $\mathrm{Mg}$ ) provenientes de las cenizas, así como al aporte significativo de iones fosfato y sulfato que se solubilizaron a partir de estos materiales.

Otro aspecto que influye de forma importante en la disponibilidad de nutrientes, es el tipo de material depositado. De acuerdo con Alvarado (1976) las cenizas de origen andesítico aportan una considerable cantidad de elementos $(\mathrm{P}, \mathrm{Ca}$, $\mathrm{Mg}, \mathrm{K}$ ), mientras que las de origen riolítico no presentan estas características.

\section{Solubilidad de las cenizas en agua}

En los análisis de solubilidad en agua de las cenizas no se detectó la presencia de $\mathrm{P}, \mathrm{Zn}, \mathrm{Cu}$ y Mn a ningún $\mathrm{pH}$ de agua ni tiempo de agitación.
En cuanto al P estos resultados concuerdan con lo descrito por Bornemisza (1971), el cual reporta no haber encontrado aniones $\mathrm{PO}_{4}^{-3}$ solubles en agua en las cenizas recién expulsadas por los volcanes Irazú y Arenal. En el caso del Mn el mismo autor también encontró muy bajas cantidades solubles, con valores que rondan los $0,08 \mathrm{ppm}$ en el caso de las muestras del volcán Irazú y valores de 0,05 a 0,40 en las cenizas provenientes del volcán Arenal.

Por otro lado, se pudo determinar la presencia de $\mathrm{Ca}, \mathrm{Mg}$, K, Na y $\mathrm{S}$ en la solución, donde el $\mathrm{Ca}$ presentó una mayor solubilidad en agua indistintamente del $\mathrm{pH}$ inicial de la solución, que llegó a alcanzar valores superiores a las 50 ppm luego de 24 h de agitación.

En relación con los resultados obtenidos por Bornemiza (1971) al analizar los aniones y cationes extraídos con agua, se puede establecer una diferencia precisamente en $\mathrm{Ca}$, ya que las cantidades de este elemento extraídas a las $18 \mathrm{~h}$ para la cenizas del Irazú y el Arenal fueron de 4,8 y 10,4 ppm, respectivamente, mientras que en el presente estudio, a las $4 \mathrm{~h}$ de las cenizas del Volcán Turrialba habían sido extraídas cantidades mayores a $20 \mathrm{ppm}$, indistintamente del pH inicial del agua.

En la Figura 1 se puede observar que para los elementos $\mathrm{Ca}, \mathrm{Mg}, \mathrm{Na}$ y $\mathrm{S}$ se presentaron aumentos significativos en cuanto a la cantidad disuelta en agua al aumentar el tiempo de agitación para los 3 distintos $\mathrm{pH}$ iniciales de la solución. Además producto de la solubilización de estos elementos en el agua también se puede apreciar un aumento significativo de la CE al incrementarse los tiempos de agitación, sin llegar a ser estos valores demasiado elevados como para considerarlos perjudiciales en los tejidos vegetales.

El K fue el único elemento que no mostró una tendencia definida en cuanto a su solubilidad en agua al variar el $\mathrm{pH}$ de la solución y el tiempo de agitación (Figura 1). Además, fue el elemento que más variación tuvo en el porcentaje de disponibilidad en solución extractora, a pesar de que los contenidos totales de las 2 muestras analizadas no mostraron gran variación (Cuadro 1). 

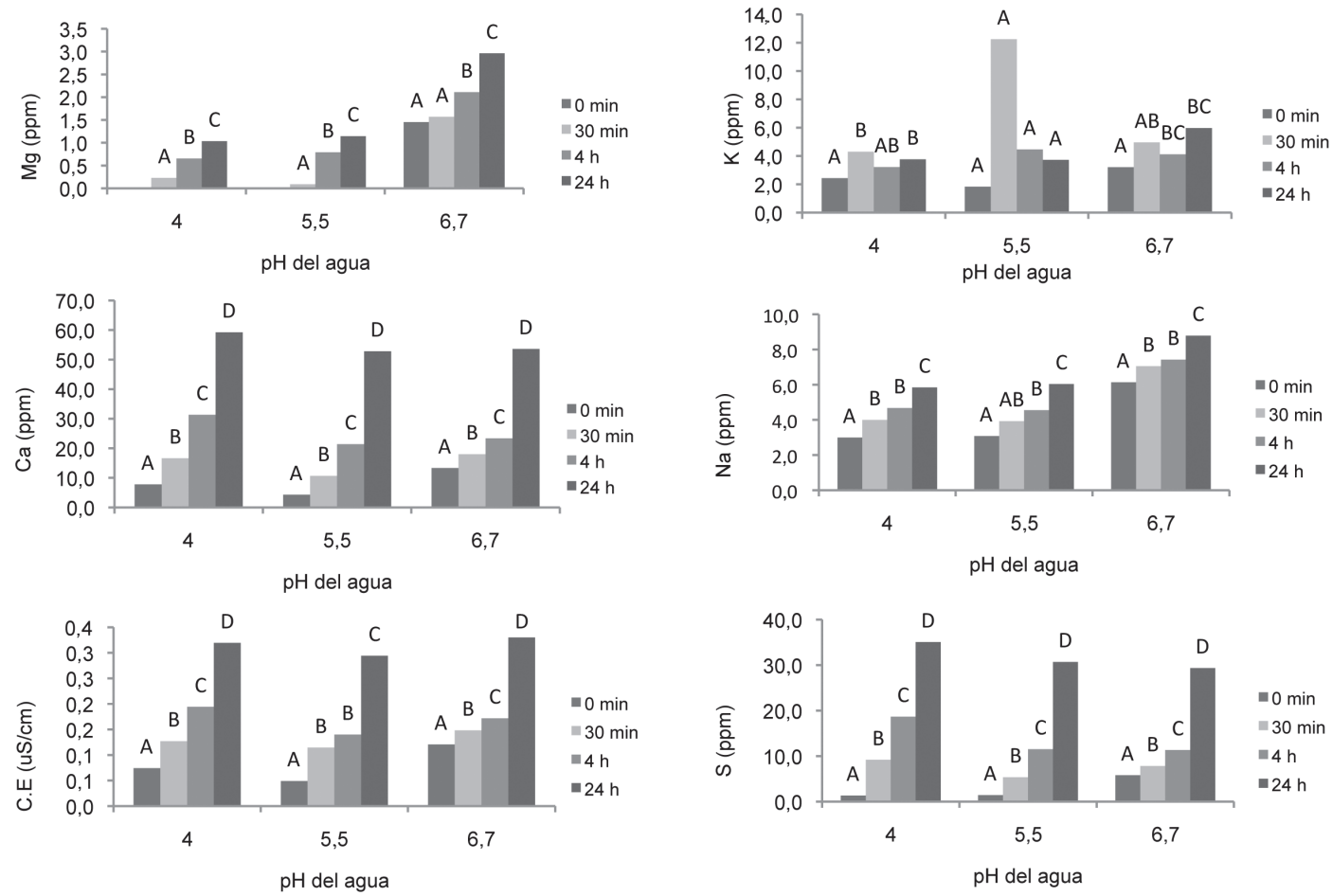

Fig. 1. Conductividad eléctrica (CE) y cantidad de $\mathrm{Ca}, \mathrm{Mg}, \mathrm{K}$, Na y $\mathrm{S}$ solubles en agua con 3 distintos pH y 4 tiempos de agitación. Barras con letra distinta entre cada grupo de datos se consideran significativamente diferentes según prueba de DMS $(\mathrm{p}<0,005)$.

Estos comportamientos poco regulares en cuanto a la solubilidad y disponibilidad del K pueden deberse principalmente a la conformación $y$ al tipo de material que dio origen a las cenizas expulsadas. Para el caso de los materiales que han dado origen a las cenizas volcánicas en la región central de Costa Rica y a las provenientes del Volcán Turrialba, algunos autores han reportado que el tipo predominante es andesítico-basáltico (Castillo 1984 y Reagan et al. 2006).

En el caso de los elementos $\mathrm{Mg}$ y $\mathrm{Na}$ las cantidades extraídas de las cenizas del Turrialba guardan semejanza con las reportadas para estos cationes por Bornemisza (1971), especialmente cuando el pH inicial de la solución fue 6,7.

El elemento $\mathrm{S}$ mostró cantidades solubles por arriba de las 10 ppm con 4 h de agitación y valores cercanos a $30 \mathrm{ppm}$ luego de ser agitadas las muestras por $24 \mathrm{~h}$, lo anterior con los $3 \mathrm{pH}$ iniciales de la solución. Estos resultados indican que la cantidad de S soluble en agua en las cenizas frescas del Volcán Turrialba son superiores a las cenizas de los volcanes Irazú y Arenal, las encontradas por Bornemisza (1971), las cuales presentaron valores de alrededor de $6 \mathrm{ppm}$ de S para el caso del Irazú y de 8 a 11 ppm para el Arenal, luego de 18 h de agitación.

Además, en el análisis de solubilidad efectuado en el presente estudio sobre la muestra de ceniza del Volcán Turrialba, se observó un efecto "buffer" por parte de la ceniza al disolverse, ya que sin importar el $\mathrm{pH}$ inicial que tuviera el agua se dio una tendencia a elevar o mantener el $\mathrm{pH}$ 


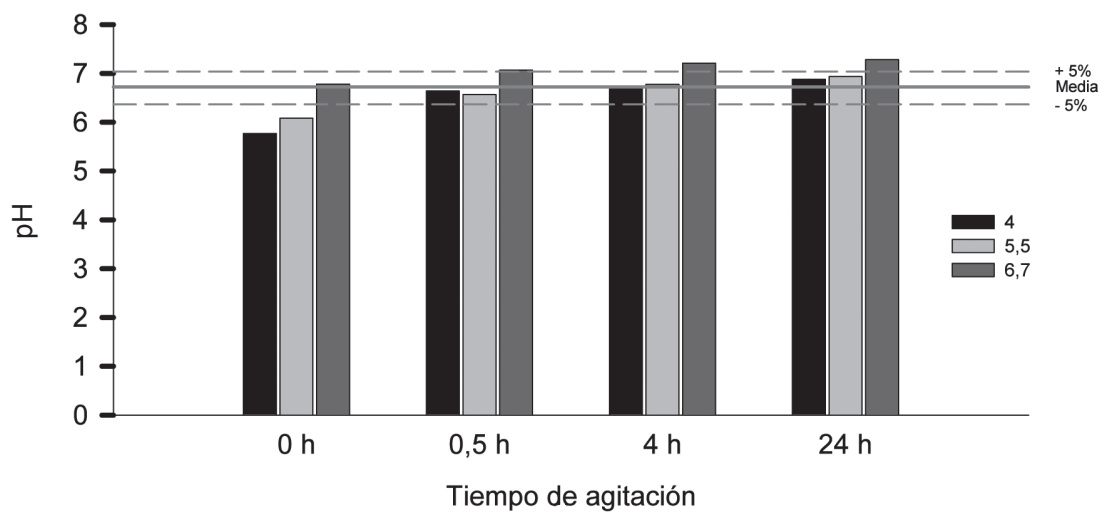

Fig. 2. pH final del la solución con ceniza a 4 tiempos de agitación $(0 ; 0,5 ; 4$ y 24 h) y 3 pH iniciales del agua. La línea continua indica la media de $\mathrm{pH}$ obtenido.

Líneas punteadas indican porcentaje de error admitido en mediciones de $\mathrm{pH}, 5 \%$.

de la solución a valores cercanos a la neutralidad, con una media general de 6,7 (Figura 2).

Los promedios de los valores de $\mathrm{pH}$ de las soluciones finales, indistintamente del $\mathrm{pH}$ inicial del agua, luego de algún tiempo de agitación coinciden con los valores reportados por el OVSICORI (2010), los cuales fueron de 6,7 para disoluciones acuosas extraídas de las cenizas recolectadas en la comunidad de La Central y de 7,1 para cenizas provenientes de La Pastora.

Al respecto Besoaín (1972) señala que en condiciones naturales, inmediatamente después de la deposición de las cenizas el pH en el medio tiende a ser ácido por efecto de los componentes sulfurados que acarrea el material; sin embargo, con las primeras precipitaciones que se den en el sitio dicha acidez disminuye considerablemente, pues dejan en la solución los componentes básicos, razón por la cual se da un aumento en el pH del medio.

En el estudio realizado por Bornemisza y Morales (1969) con cenizas recién expulsadas por el Volcán Irazú se menciona que los pH en agua de estas muestras presentaron valores de 5,1 , razón por la cual estos autores sugieren que la acidez de estos materiales no sería la responsable directa de los daños causados a los cultivos.
De esta forma, cualquier repercusión negativa relacionada con algún tipo de quema en los tejidos vegetales de las plantaciones que se encuentren en el área de influencia del Volcán Turrialba se podría asociar a otros factores relacionados con la actividad volcánica como lo son la lluvia ácida y la emisión de ciertos gases, y no a la deposición de cenizas directamente.

Valores de $\mathrm{pH}$ de lluvias ácidas de hasta 3,02 han sido reportados por el OVSICORI (2010) en las aguas de lluvia de comunidades aledañas al Volcán mediante monitoreos constantes en la zona realizados desde el 2007. Con estos valores de $\mathrm{pH}$ por debajo de 4 la probabilidad de que se produzcan daños a nivel foliar incrementan considerablemente. Un ejemplo de ello es lo documentado por Lee et al. (1981), quienes encontraron lesiones foliares considerables en 31 de 35 cultivos sometidos a simulaciones de lluvia ácida con valores de $\mathrm{pH}$ de 3 .

\section{CONCLUSIONES}

A pesar de los altos contenidos totales de Fe en la composición de las cenizas volcánicas estudiadas, su disponibilidad en la solución Olsen 
Modificada fue la más baja de todos los elementos analizados $(0,2 \%$ con respecto al total).

Ninguno de los elementos en estudio superó el 16\% de disponibilidad en la solución extractora, por lo cual se podría esperar que no tengan influencia significativa, ni tóxica ni beneficiosa, en el estado nutricional de los suelos a corto plazo.

A mediano plazo, una vez que se dé el proceso de mineralización de los materiales depositados, los efectos en la parte de fertilidad de los suelos se pueden hacer más evidentes.

La solubilidad en agua de los elementos $\mathrm{Ca}, \mathrm{Mg}, \mathrm{S}$ y $\mathrm{Na}$ aumentó significativamente al aumentar el tiempo de agitación sin importar el $\mathrm{pH}$ inicial de la solución. En las muestras analizadas los contenidos de Ca y $\mathrm{S}$ solubles en agua fueron mayores en las cenizas frescas provenientes del Volcán Turrialba en comparación con las del Volcán Irazú y el Volcán Arenal reportadas por otros autores.

La ceniza analizada se puede catalogar de reacción neutra, ya que indistintamente del pH inicial de la solución y tiempo de agitación, alcanza valores en solución cercanos a 6,7, por lo que no se esperaría que tuviera un efecto directo en la quema de los tejidos vegetales.

\section{LITERATURA CITADA}

ALVARADO A. 1976. Efectos favorables de actividades volcánicas en suelos. Revista Geofísica 5:45-48.

ALVARADO A., BERTSCH F., BORNEMISZA E., CABALCETA G., FORSYTHE W., HENRIQUEZ C., MATA R., MOLINA E., SALAS R. 2001. Suelos derivados de cenizas volcánicas (Andisoles) de Costa Rica. ACCS. San José, Costa Rica. 111 p.

BESOAÍN E. 1972. Mineralogía de arcillas de algunos suelos volcánicos de Costa Rica, pp. 249-278. In: M. Blasco y R. Guerrero (eds). $2^{\circ}$ Panel sobre suelos volcánicos de América. IICA.

BORNEMISZA E. 1971. Extraction of anions and cations from recent volcanic ash. Soil Sc. Soc. Am. Proc. 35(3):506-507.
BORNEMISZA E., MORALES J.C. 1969. Soil chemical characteristics of recent volcanic ash. Soil Sc. Soc. Am. Proc. 33:528-530.

CASTILLO R. 1984. Geología de Costa Rica: una sinopsis Editorial de la Universidad de Costa Rica. San José, Costa Rica. 182 p.

CHAVERRI D., ALVARADO A. 1979. Cambios químicos de importancia agrícola sufridos por las cenizas del Volcán Irazú en 15 años. Agronomía Costarricense 3(2):181-182.

DAHLGREN R., UGOLINI F., CASEY W. 1999. Field wathering rates of Mt. St. Helens tephra. Geochimica et Cosmochimica Acta 63:587-598.

DÍAZ-ROMEU R., HUNTER A. 1978. Metodologías de muestreo de suelos, análisis químico de suelos y tejido vegetal y de investigación en invernadero. CATIE. Turrialba, Costa Rica, 62 p.

HENRÍQUEZ C., CABALCETA G. 1999. Guía práctica para el estudio introductorio de los suelos con un enfoque agrícola. ACCS. San José, Costa Rica. 111 p.

ISAAC R., JOHNSON W. 1997. Elemental determination by inductively coupled plasma atomic emission spectrometry, pp. 165-170. In: Y. Kalra (ed) Handbook of Reference Methods for Plant Analysis. CRC Press.

LEE J., NEELY G., PERRIGAN S., GROTHAUS L. 1981. Effect of simulated sulfuric acid rain o yield, growth and foliar injury of several crops. Environmental and Experimental Botany 21(2):171-185.

NANZYO M. 2002. Unique properties of volcanic ash soils Global Environmental Research 6:99-112.

REAGAN M., DUARTE E., SOTO G.J., FERNÁNDEZ E. 2006. The eruptive history of Turrialba volcano, Costa Rica, and potential hazards from future eruptions, pp. 235-257. In: W.I. Rose, G.J.S. Bluth, M.J. Carr, J.W. Ewert, L.C. Patino, y J.W. Vallance (eds). Volcanic hazards in Central America: Geological Society of America Special Paper 412. Geological Society of America.

SOLEY A. 1966. Efecto de la ceniza volcánica sobre suelos y subsuelos ácidos. Tesis de licenciatura, Universidad de Costa Rica, San José, Costa Rica. 76 p.

UGOLINI F., DAHLGREN R. 2002. Soil development in volcanic ash. Global Environmental Research 6:69-81. 